Revisão de literatura - 355 -

\title{
ASPECTOS DE BIOSSEGURANÇA RELACIONADOS AO USO DO JALECO PELOS PROFISSIONAIS DE SAÚDE: UMA REVISÃO DA LITERATURA
}

\author{
Carmem Milena Rodrigues Siqueira Carvalhoํ․, Maria Zélia de Araújo Madeira², Fabrício Ibiapina Tapety³, \\ Eucário Leite Monteiro Alves ${ }^{4}$, Maria do Carmo de Carvalho Martins ${ }^{5}$, José Nazareno Pearce de Oliveira Brito ${ }^{6}$
}

\footnotetext{
${ }^{1}$ Doutora em Dentística e Endodontia. Professora da Faculdade de Saúde, Ciências Humanas e Tecnológicas do Piauí (NOVAFAPI) e Universidade Federal do Piauí (UFPI). Piauí, Brasil. E-mail: ccarvalho@novafapi.com.br

${ }^{2}$ Mestre em Educação. Docente do Curso de Graduação em Enfermagem da UFPI. Piauí, Brasil. E-mail: zeliamadeira15@yahoo. com.br

${ }^{3}$ Doutor em Odontologia. Professor da Faculdade NOVAFAPI. Piauí, Brasil. E-mail: ftapety@novafapi.com.br, fabricio100@ hotmail.com

${ }^{4}$ Médico. Professor do curso de Medicina da Faculdade NOVAFAPI. Piauí, Brasil. E-mail: medicina@novafapi.com.br

${ }^{5}$ Doutora em Ciências Biológicas. Docente do Departamento de Biofísica e Fisiologia da Faculdade NOVAFAPI e da UFPI. Piauí, Brasil. E-mail: mcmartins@novafapi.com.br

${ }^{6}$ Doutor em Ciências Médicas. Docente do Curso de Graduação em Medicina da Faculdade NOVAFAPI e da UFPI. Piauí, Brasil. E-mail: nazapearce@novafapi.com.br
}

RESUMO: O estudo objetivou analisar a literatura publicada a respeito dos aspectos da biossegurança relacionados ao uso do jaleco pelos profissionais da saúde. Trata-se de uma revisão narrativa da literatura publicada no período de 1991 a 2008. Utilizou-se as bases de dados MEDLINE, LILACS e SciELO, sendo selecionados 22 artigos que foram agrupados para análise considerando os enfoques priorizados em: infecções cruzadas causadas por jalecos; jalecos contaminados; flora bacteriana em jalecos dos profissionais de saúde. O jaleco foi abordado como fonte de contaminação e como equipamento de proteção individual na prevenção das infecções. Portanto, são necessárias campanhas educativas no sentido de orientar os profissionais de saúde sobre o uso de jaleco.

DESCRITORES: Infecção. Biossegurança. Prevenção.

\section{BIOSECURITY ASPECTS RELATED TO THE USE OF LABORATORY COATS BY HEALTH PROFESSIONALS: A LITERATURE REVIEW}

\begin{abstract}
This study aimed to analyze the literature published in regards to biosecurity aspects of the use of laboratory coats by health professionals. This is a narrative review of the literature published from 1991 to 2008. MEDLINE, LILACS, and SciELO were the databases used. Twenty-two articles were selected and were grouped for analysis with emphasis given to: cross infections caused by lab coats; contaminated lab coats; bacterial flora on health professionals' lab coats. The lab coat was found to be a source of contamination and to be equipment for individual protection in infectious disease. Therefore educational campaigns are necessary in order to orientate health professionals about the use of lab coats.
\end{abstract}

DESCRIPTORS: Infection. Biosecurity. Prevention.

\section{ASPECTOS DE BIOSEGURIDAD RELACIONADOS AL USO DEL JALECO POR PROFESIONALES DE SALUD: UNA REVISIÓN BIBLIOGRÁFICA}

RESUMEN: El objetivo del estudio fue analizar la literatura publicada sobre los aspectos de bioseguridad relacionados al uso del jaleco por profesionales del área de la salud. Se trata de una revisión narrativa de la literatura publicada en el período de 1991 a 2008. Se utilizaron las bases de datos MEDLINE, LILACS y SciELO, siendo seleccionados 22 artículos que fueron agrupados para su análisis considerando los enfoques cuyo énfasis es dado en: infecciones cruzadas causadas por los jalecos; jalecos contaminados; flora bacteriana presente en los uniformes de los profesionales de salud. El jaleco fue considerado como fuente de contaminación y como equipo de protección individual en la prevención de las infecciones. Por lo tanto, son necesarias campañas educativas en el sentido de orientar los profesionales de salud sobre el uso del jaleco.

DESCRIPTORES: Infección. Bioseguridad. Prevención. 


\section{INTRODUÇÃO}

Na prevenção da contaminação por agentes infecciosos, recomenda-se que os profissionais de saúde adotem medidas de Biossegurança, especificamente àqueles que trabalham em áreas insalubres, com risco variável.

Esses riscos dependem da hierarquização e complexidade dos hospitais ou posto de saúde, do tipo de atendimento realizado (hospital de doenças infecto-contagiosas) e do ambiente de trabalho do profissional (endoscopia, unidade de terapia intensiva, lavanderia, laboratório etc), uma vez que estão mais suscetíveis a contrair doenças advindas de acidentes de trabalho, por meio de procedimentos que apresentam riscos.

Biossegurança é definida como o conjunto de ações voltadas para a prevenção, minimização ou eliminação de riscos inerentes às atividades de pesquisa, produção, ensino, desenvolvimento tecnológico e prestação de serviços, riscos que podem comprometer a saúde do homem, dos animais, do meio ambiente ou a qualidade dos trabalhos desenvolvidos. ${ }^{1-2}$

Em relação à Biossegurança, é importante relacionar à sua legalização no Brasil, que atualmente está veiculada à Lei $\mathrm{N}^{\circ} 11.105$ de 25 de março de 2005 que dispõe sobre a Política Nacional de Biossegurança. A Lei $N^{\circ}$ 8.974, de 5 de janeiro de 1995 foi revogada, criou a Comissão Técnica Nacional de Biossegurança, uma dimensão ampla que extrapola a área da saúde e do trabalho, sendo empregada quando há referência ao meio ambiente e à biotecnologia. ${ }^{1}$

Nesse sentido, a saúde dos trabalhadores abrange um campo específico da área da saúde pública no Brasil, que procura atuar através de procedimentos próprios, com a finalidade de promover e proteger a saúde das pessoas envolvidas no exercício do trabalho. Assim, voltada para a saúde do trabalhador, tem-se a Portaria $N^{\circ} 37$ de 06/12/2002, que instituiu a Norma Regulamentadora (NR) 32, que trata especificamente da Segurança e Saúde do Trabalho nos Estabelecimentos de Assistência a Saúde. ${ }^{3}$

Considerando esses aspectos, no ambiente hospitalar, o risco é uma ou mais condições de uma variável com potencial necessário para causar danos. ${ }^{3}$ De acordo com a NR-9 do Ministério do Trabalho e Emprego, os riscos de acidentes podem ser classificados em: físicos (calor, iluminação e artigos cortantes); químicos (soluções químicas e aerossóis); biológicos (fluidos corporais - vírus, bactérias e fungos); ergonômico-mecânicos (desconforto); e psicossociais (estresse e fadiga). ${ }^{4}$

Dentre estes, o risco biológico como um dos principais entre os profissionais de saúde, aumentou, principalmente após o aparecimento da Aids e do crescimento do número de pessoas infectadas pelos vírus da hepatite $\mathrm{B}$ e C. ${ }^{3}$

Com o advento da aids e a divulgação por parte dos meios de comunicação dos riscos a que estão submetidos durante, por exemplo, tratamentos odontológicos, a população passou a exigir mais e, principalmente, a valorizar aqueles profissionais que investem em biossegurança. ${ }^{5}$

É importante salientar que nos serviços de saúde, especialmente de urgência e emergência, grande parte dos acidentes que envolvem profissionais da área da saúde se deve à falta de observância e adoção das normas de biossegurança. ${ }^{4}$

Contudo, o emprego de práticas seguras, como o uso do jaleco, reduz significativamente o risco de acidente ocupacional, sendo importante também a conscientização dos profissionais para utilização de técnicas assépticas e o estabelecimento de normas, conduta e procedimentos que garantam ao profissional e ao paciente um tratamento sem risco de contaminação.

Nos serviços de saúde as infecções são consideradas problemas de saúde pública, devido à sua importante incidência e influência nas taxas de letalidade, especialmente nos hospitais. Apesar de tantos exemplos, como as infecções pós-cirúrgicas, transmissão da hepatite $B$, do herpes simples, entre tantas outras, os profissionais da área de saúde responsáveis pela prevenção e controle nem sempre estiveram conscientes disso e nem propensos a seguir de forma correta os passos necessários para eliminar e diminuir os riscos para seus pacientes e para si próprios e sua equipe.

Nas infecções cruzadas, os microrganismos têm um papel passivo, cabendo ao homem o papel ativo; logo, será sobre suas ações o maior enfoque do controle dessas infecções. Atualmente, as normas consoantes à biossegurança são motivos de preocupação, tanto por parte das Comissões de Controle de Infecção Hospitalar quanto pelos Serviços de Medicina Ocupacional. A utilização de precauções básicas auxilia os profissionais nas condutas técnicas adequadas à prestação dos serviços, através do uso correto de Equipamento de Proteção Individual (EPI), de acordo com a NR-6 da portaria No 3.214, de 08.06.78. Essas medidas devem gerar melhorias na qualidade da assistência e diminuição de custos e infecções cruzadas advindas da prática hospitalar 
e ambulatorial, tanto para os profissionais como para os pacientes e seus familiares. ${ }^{6-7}$

Dentre as medidas destacam-se os EPIs, que se destinam a proteger os profissionais nas operações de riscos de exposição ou quando houver manipulação de produtos químicos e biológicos, bem como riscos de contaminação com materiais perfurocortantes. Os EPIs podem ainda ser considerados um dispositivo de uso individual destinado a proteger a integridade física e a saúde do trabalhador. ${ }^{7-8}$

A contaminação da pele e vestimentas (roupas) por respingos e por toque é praticamente inevitável em hospitais e ambulatórios, assim como em consultórios odontológicos. ${ }^{8}$ Estudo demonstrou que as roupas são uma importante via de transmissão de infecção no ambiente hospitalar. ${ }^{9}$ Desta forma, os jalecos dos profissionais da área de saúde, passam a ser o primeiro sítio de contato em termos de indumentária com a pele, líquidos e secreções dos pacientes, tornando-se com isto um verdadeiro fômite.

Bactérias multirresistentes, que podem provocar doenças como faringites, otites, pneumonia, tuberculose e até mesmo a morte, são carregadas para lugares públicos e retornam das ruas para consultórios médicos, odontológicos, enfermarias e salas de cirurgia nos jalecos dos mais diversos profissionais de saúde. Freqüentemente, a seriedade da questão é negligenciada por arrogância ou desconhecimento de alguns conceitos básicos de microbiologia. ${ }^{10}$

Em restaurantes e lanchonetes da região hospitalar de muitas cidades, observam-se, diariamente, médicos, enfermeiros, odontólogos e outros profissionais de saúde paramentados com seus aventais de mangas compridas, gravatas, estetoscópios no pescoço e até mesmo vestimentas específicas para áreas cirúrgicas. Essa cena se repete em outros locais da cidade onde funcionam hospitais, consultórios, laboratórios de análises, clínicas médicas e veterinárias. Além de constituir grave ameaça à saúde pública, esses profissionais (e os estabelecimentos onde trabalham) são passíveis de representações nos órgãos de defesa do consumidor e podem ser punidos com pesadas multas. Na Inglaterra, a Associação Médica Britânica estabeleceu diretrizes rigorosas para o problema. A entidade condena o uso de gravatas, relógios de pulso, adornos e, sobretudo, o hábito de circular com aventais e jalecos em ambientes não hospitalares, já que vários germes capazes de provocar doenças foram isolados, principalmente nas mangas e nos bolsos dessas indumentárias. ${ }^{10}$
Muitos profissionais da saúde alegam não haver estudos científicos conclusivos que avaliem o impacto dos jalecos nas taxas de infecção hospitalar e por isso passam a freqüentar os mais diversos ambientes usando seus uniformes.

Diante dessas considerações, o estudo teve como objetivo fazer uma análise da literatura publicada a respeito dos aspectos da biossegurança relacionados ao uso do jaleco pelos profissionais da saúde.

\section{METODOLOGIA}

Trata-se de uma revisão narrativa da literatura, que apresenta uma temática mais aberta, não exigindo um protocolo rígido para sua confecção, a busca das fontes não é pré-determinada e específica, sendo frequentemente menos abrangente. A seleção dos artigos é arbitrária, provendo o autor de informações sujeitas a viés de seleção, com grande interferência da percepção subjetiva. ${ }^{11}$

A forma de busca do material foi nas bases de dados MEDLINE, LILACS e SciELO, utilizando como limitação temporal o período de 1991 a 2008. Foram utilizadas as palavras chaves: infecção, biossegurança, prevenção e controle, conforme apresentação do vocabulário contido nos Descritores em Ciências da Saúde, criados pela Bireme. Com esses termos, selecionou-se, de forma arbitrária, um total de 22 artigos pertinentes ao tema abordado onde os critérios de inclusão foram a presença das palavras-chave selecionadas e a limitação temporal do período.

Os textos foram agrupados para análise considerando os enfoques priorizados em: infecções cruzadas causadas por jalecos, jalecos contaminados, flora bacteriana em jalecos, padrões e normas para descontaminação de jalecos dos profissionais de saúde. Considerou-se também no estudo os artigos descritos na literatura que utilizavam como sinônimo de jaleco o avental, o casaco e a bata.

\section{RESULTADOS E DISCUSSÃO}

\section{O jaleco como fonte de contaminação}

Estudo realizado demonstrou que uniformes e jalecos brancos tornaram-se progressivamente contaminados durante atendimentos clínicos e que a contaminação alcança um nível de saturação até se estabilizar em um platô. O tempo que é gasto para se atingir este nível de saturação não está claro e é provável que dependa da quantidade de colonização 
microbiana do paciente, freqüência e tipo de atividade clínica e outros fatores, tais como: o nível de contaminação microbiana ambiental e a extensão e o uso efetivo de roupa protetora. Assim, os autores concluíram que os uniformes tornavam-se contaminados durante atendimentos, sugerindo a hipótese que aqueles uniformes são um veículo potencial para transmissão de microrganismos, o que pode vir a causar infecções associadas a cuidados de saúde. ${ }^{12}$

Existe uma significante preocupação do público, na Inglaterra, a respeito dos profissionais que usam uniformes em locais públicos e estes, se contaminados, podem contribuir para a disseminação de infecções associadas aos cuidados de saúde. Evidências de uma conexão entre uniformes contaminados e que infecções podem contribuir para a disseminação de patógenos em ambientes não foi medido sistematicamente. Estudos em pequena escala, mostram que uniformes e jalecos brancos tornam-se, progressivamente, contaminados durante os atendimentos clínicos, e a maioria da contaminação microbiana se origina do usuário para o uniforme. ${ }^{12}$

Nesta perspectiva, o uso diário do jaleco pelo profissional de saúde no contato com pacientes faz com que os jalecos se tornem colonizados com bactérias patogênicas? Esta hipótese foi confirmada em pesquisa na qual foi demonstrado que os jalecos brancos de estudantes de medicina são mais susceptíveis de estarem bacteriologicamente contaminados em pontos de contato freqüente, como mangas e bolsos. Os principais microrganismos identificados foram comensais de pele incluindo o Staphylococcus aureus. Para os autores, a limpeza dos jalecos realizada pelos estudantes, foi correlacionada com a contaminação bacteriológica, e apesar disso, uma proporção significativa dos estudantes lavava os seus jalecos somente ocasionalmente. Estudantes de medicina em treinamento hospitalar deveriam considerar a hipótese de assumirem o compromisso de terem seus jalecos sempre lavados recentemente. Este estudo apóia a opinião de que os jalecos brancos dos estudantes constituem uma fonte potencial de infecção cruzada em enfermarias e que seu modelo deveria ser modificado, de modo a facilitar a lavagem das mãos. ${ }^{13}$

O papel dos trabalhadores da saúde na prevenção da transmissão de infecção nosocomial e a importância da lavagem das mãos, uma das práticas mais importantes para os profissionais da área de saúde, pois é uma conduta simples, de baixo custo e muito importante na prevenção da infecção. ${ }^{14}$ Há pouca evidência de outros métodos melhores que a lavagem das mãos na prevenção de infecção hospitalar, independente do tipo de jaleco que os profissionais estejam usando. ${ }^{15}$

Também em relação à contaminação microbiológica, alguns estudos concluíram que os Staphylococcus aureus resistentes à Meticilina (MRSA) prevaleciam em duas alas em suas escolas médicas de um hospital universitário, durante o período de julho a setembro de 1997. ${ }^{16-17}$ Para determinar se estes Staphylococcus aureus isolados foram associados a fatores ambientais, realizaram-se dois inquéritos seqüenciais MRSA com o pessoal hospitalar e arredores, em enfermarias com surtos (alas 1 e 2) e em uma enfermaria sem um foco (enfermaria 3), em abril de 1998 (enfermaria apenas 1) e em março de 1999 (enfermarias 1, 2, e 3). Nos dois inquéritos seqüenciais, cepas MRSA foram detectadas principalmente a partir de casacos brancos.

Pesquisadores relataram que os uniformes dos profissionais de saúde, incluindo os jalecos, quando em uso, tornam-se progressivamente contaminados com bactérias de baixa patogenicidade provenientes do usuário e de patogenicidade mista provenientes do ambiente clínico e de pacientes. ${ }^{17}$ A hipótese que os uniformes ou as roupas poderiam ser um veículo para transmissão de infecção não são suportadas por evidências. Todos os componentes do processo de lavagem contribuem para remover ou matar os microrganismos. Não existem trabalhos científicos que estabeleçam se há diferenças na eficácia da descontaminação de uniformes entre as lavanderias industriais e as domésticas ou que a lavagem doméstica promova uma inadequada descontaminação.

\section{O jaleco como equipamento de proteção individual na prevenção de infecção}

Segundo pesquisadores, ainda não se apresentou o isolamento de bactérias patogênicas, uma vez que muitos destes microrganismos precisam de um ambiente úmido e seco para sua sobrevivência, o que não está presente em jalecos brancos. ${ }^{18}$

Por outro lado, alguns acessórios que ficam em contato direto com os jalecos dos profissionais de saúde como crachás de identificação, colares e brincos usados por muitos profissionais, podem estar contaminados com bactérias patogênicas às quais poderiam ser transmitidas a pacientes. Desta forma no estudo, são sugeridas intervenções de controle de infecções apropriadas. Crachás de identificação, mesmo não parecendo ser a principal fonte de microrganismos patogênicos, podem abri- 
gar organismos de doença e deveriam ser limpos regularmente, o que pode ser aplicado a jalecos. ${ }^{19}$

Desse modo, a prevenção se faz através da utilização das precauções padrão, medidas de proteção que devem ser tomadas por todos os profissionais de saúde, quando prestam cuidados aos pacientes ou manuseiam artigos contaminados, independentes da presença de doença transmissível comprovada, como por exemplo, o uso de EPIs (luvas, máscaras, gorros, óculos de proteção, aventais e botas), lavagem das mãos, descarte adequado de roupas e resíduos, material perfurocortante adequadamente acondicionado e todos os profissionais vacinados contra a Hepatite B. ${ }^{18}$

Em relação ao papel dos jalecos médicos na transmissão e prevenção de infecções nosocomiais, ${ }^{20}$ outro estudo concluiu que uma maior atenção deveria ser feita em relação à vestimenta de jalecos da equipe de saúde, sendo que muitas vezes seu papel protetor é superestimado.

O avental e as luvas são importantes para a terapia em um paciente, quando houver possibilidade de contato com fluidos corpóreos e devem ser removidos após o uso, pois podem facilmente veicular microrganismo. ${ }^{14}$ Investigação realizada aponta o fato de os alunos utilizarem transporte coletivo vestidos com jalecos, além de freqüentarem cantinas e restaurantes sem a mínima preocupação em estar portando uma roupa com grande chance de estar contaminada. ${ }^{21}$

As luvas, por apresentarem menos porosidades e reentrâncias que a pele, possibilitam uma melhor desinfecção, além de conferir natural proteção à contaminação. Luvas devem cobrir os punhos do avental, que deve ter mangas compridas e ser mantido fechado; a máscara deve apresentar paredes duplas ou triplas e se ajustar confortavelmente aos óculos de proteção; os propés devem ser utilizados ou reserva-se um par de sapatos para uso exclusivo no consultório. ${ }^{22}$

A atenção às estratégias preventivas simples podem reduzir significativamente as taxas de infecções cruzadas. ${ }^{23}$ Dentre elas, a lavagem freqüente das mãos continua sendo a mais importante medida no controle das infecções. No entanto, identificar mecanismos para garantir o cumprimento pelos profissionais de saúde continua a ser um problema de alta complexidade.

Em um estudo prospectivo observacional foi analisada a obediência ao uso rotineiro de capotes por trabalhadores de saúde e visitantes não trabalhadores de saúde, quando entravam em quartos de pacientes sob precauções de contato. Concluí-se que havia uma melhoria na transmissão de patógenos e que a obediência do uso do capote requer esforços educacionais mais intensos. ${ }^{24}$

As luvas, batas e máscaras têm um papel a desempenhar na prevenção das infecções, mas muitas vezes são usados inadequadamente, aumentando os custos de serviços desnecessariamente. Enquanto microrganismos virulentos podem ser cultivados a partir de estetoscópios e casacos brancos, seus papéis na transmissão de doenças permanecem indefinidos. Tal como o estetoscópio, o casaco branco foi durante muito tempo um símbolo do profissional de saúde, assim, muitas instituições insistem para que médicos, em especial, o vistam como parte de um código obrigatório. Cerca de metade dos pacientes continua a preferir o seu médico de jaleco branco. ${ }^{23}$

No entanto, os pacientes podem ficar menos entusiasmados, se compreenderem que casacos brancos constituem fontes potenciais de agentes patogênicos e é fonte de infecção cruzada, particularmente em áreas cirúrgicas. ${ }^{25}$

A recomendação é que os jalecos devem ser removidos em sacos plásticos e em uma freqüência superior a uma semana. Devem ser seguidas regras simples de biossegurança para assegurar a saúde dos profissionais e dos pacientes no controle de doenças. ${ }^{26}$

\section{CONCLUSÃO}

Os resultados deste estudo apontam no sentido de que os jalecos, bem como outros acessórios usados pelos profissionais da área de saúde, são um veículo potencial para transmissão de microrganismos podendo vir a servir como fonte de infecções associadas aos cuidadores de saúde.

O uso de jalecos se tornou uma prática obrigatória, com a finalidade de proteção dos profissionais durante a realização de procedimentos a pacientes, que envolvam material biológico, no entanto sua utilização indevida (como uso fora do ambiente de trabalho) pode causar sérias conseqüências para a saúde pública.

Pode-se dizer que há poucos estudos em relação à contaminação de uniformes utilizados por profissionais da área de saúde. É necessário que se realizem mais pesquisas para verificar a observância da existência de infecção cruzada por vestimentas utilizadas pelas equipes médicas multidisciplinares.

Sugere-se a realização de campanhas educativas no sentido de orientar os profissionais de saúde sobre o uso de jaleco e a adoção de proto- 
colos rígidos no uso e descontaminação de jalecos por parte das instituições de saúde.

\section{REFERENCIAS}

1. Hinrichsen SL. Lei de Biossegurança Nacional: alguns aspectos importantes. In: Hinrichsen SL. Biosseguranca e controle de infecções: risco sanitário hospitalar. Rio de Janeiro (RJ): MEDSI; 2004.

2. PradeSS, Oliveira ST, Rodrigues R, Nunes FA, Félix JK, Pereira M. Estudo brasileiro da magnitude das infecções hospitalares em hospitais terciários. Rev Control Infec Hosp. 1995 Mar-Jul; 2(2):11-24.

3. Mastroeni MF. Introdução à biosseguranca. In: Mastroeni MF. Biosseguranca aplicada a laboratório e serviços de saúde. São Paulo (SP): Atheneu; 2006.

4. Valle, ARMC, Feitosa MB, Araújo VMD, Moura MEB, Santos AMRS, Monteiro CFS. Representações sociais da biossegurança por profissionais de enfermagem de um serviço de emergência. Esc Anna Nery Rev Enferm. 2008 Jun; 12(2):304-9.

5. Gerbert B, Maguire BT, Spitzer. S. Patient's atitudies toward dentistry and AIDS. J Am Dent Assoc. 1989 Nov; Suppl:16s-21.

6. Santos Junior AF, Schindler Junior AFR, Pinto AM. Emprego do plano seqüência no gerenciamento da roupa hospitalar: avaliação de aspectos de biossegurança. Rev Prática Hospitalar. 2005 MarAbr; 7(38):1-6.

7. Skraba I, Nickel R, Wotkoski SR. Barreiras de contenção: EPI e EPCs. In: Mastroeni MF. Biosseguranca aplicada a laboratório e serviços de saúde. São Paulo (SP): Atheneu; 2006.

8. Littlechild P, Macmillan A, White MM, Steedman D. Contamination of skin and clothing of accident and emergency personnel. BMJ. 1992 Jul 18; 305(6846): 156-7.

9. Hambraeus A, Ransjö U. Attempts to control clothesborne infection in a burn unit. 1. Experimental investigations of some clothes for barrier nursing. J Hyg (Lond). 1977 Oct; 79(2):193-202.

10. Dias Júnior, P.P. Jaleco: uso correto na hora certa, em local apropriado. Rev Eletrônica Ciências [online]. 2008 Mai [acesso em 2008 Mai 10]; (43). Disponível em: http://www.cdcc.usp.br/ciencia/artigos/ art_43/editorial_ed43.html

11. Rother ET. Revisão sistemática $X$ revisão narrativa. Acta Paul Enferm. 2007; 20(2):5-6.

12. Loveday HP, Wilson JA, Hoffman PN, Pratt RJ. Public perception and the social and microbiological significance of uniforms in the prevention and con- trolof healthcare-associated infections: an evidence review. Br J Infec Control. 2007 Sept; 8(4):10-21.

13. Loh W, Ng VV, Holton J. Bacterial flora on the white coats of medical students. J Hosp Infect. 2000 May; 45(1):65-8.

14. Matsumoto T. The role of health care workers in nosocomial infection transmission. Nippon Rinsho. 2002 Nov; 60(11):2103-6.

15. Blom BC, Pedrosa TMG. Lavagem das Mãos. In: Couto RC, Pedrosa TMG, Nogueira JM. Infecção Hospitalar Epidemiologia e Controle. Rio de Janeiro (RJ): Medsi, 1999. p. 253-8.

16. Osawa K, Baba C, Ishimoto T, Chida T, Okamura N, Miyakes S, Yoshizawa Y. Significance of methicillinresistant Staphylococcus aureus (MRSA) survey in a university teaching hospital. J Infect Chemother. 2003 Jun; 9(2):172-7.

17. Wilson JA, Loveday HP, Hoffman PN, Pratt RJ. Uniform: an evidence review of the microbiological significance of uniforms and uniform policy in the prevention and control of healthcare-associated infections. Report to the Department of Health (England). J Hosp Infect. 2007 Aug; 66(4):301-7.

18. Kotsanas D, Scott C, Gillespie EE, Korman TM, Stuart RLMed J Aust. What's hanging around your neck? Pathogenic bacteria on identity badges and lanyards. Med J Aust. 2008 Jan 7; 188(1):5-8.

19. Ota K, Profiti R, Smaill F, Matlow AG, Smieja M. Identification badges: a potential fomite? Can J Infect Control. 2007 fall; 22(3):162-6.

20. Grys E, Pawlaczyk M. Does a physician's apron protect against nosocomial infection?. Ginekol Pol. 1996 Jun; 67(6):309-12.

21. Carvalho PR, Amaral MAZ. A Biossegurança na Universidade Brasileira. Rev Laes \& Haes. 2000 Dez; 22(128):118-26.

22. Guandalini, S.L. Biossegurança. J Bra Odont Clin. 1997; 1(1):9-11.

23. Menahem S, Shvartzman P. Is our appearance important to patients?. Fam Pract.1998 Oct; 15(5):391-7.

24. Manian FA, Ponzillo JJ. Compliance with routine use of gowns by healthcare workers (HCWs) and non$\mathrm{HCW}$ visitors on entry into the rooms of patients under contact precautions. Infect Control Hosp Epidemiol. 2007 Mar; 28(3):337-40.

25. Wong D, Nye K, Hollis P. Microbial flora on doctors' white coats. BMJ. 1991 Dec; 303 (6817):1602-4.

26. Saloojee H, Steenhoff A. The health professional's role in preventing nosocomial infections. Postgrad Med J. 2001 Jan; 77(903):16-9. 